\title{
Earthlearningidea: promoting deep questioning in lab and field
}

Chris King, Peter Kennett, Elizabeth Devon

36 Portway, Wells, Somerset, BA5 2BN, UK

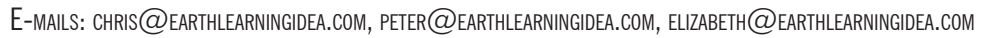

Abstract: The Earthlearningidea website (www.earthlearningidea.com) launched in 2008 as part of the International Year of Planet Earth, publishes geoscience teaching ideas online as free-to-download pdfs. The website publishes a new idea every two weeks, so that more than 280 ideas have now appeared in English. Translators around the world kindly offered to translate the ideas into their own languages and more than 900 translations can now be accessed through the website. So far, nearly 3.5 million pdfs of the ideas have been downloaded across the world at a mean rate more than 40,000 per month. The activities have been used in teacher troaining in a number countries, as recorded in the Earthlearningidea blog at http://earthlearningidea. blogspot.co.uk/. An analysis was published in 2016 of the different approaches used in the ideas published to that date. The analysis $(n=250)$ showed that some ideas covered several categories, and that overall coverage was: basic skills, $4 \%$; observation, $16 \%$; illustration $39 \%$; investigation, $10 \%$; diagrammatic models, $5 \%$; physical models, $44 \%$; thought experiments, $13 \%$ and unattributed, $12 \%$. The thought experiments were deliberately focused on promoting deep understanding through deep questioning in the lab and field. They include examples such as: 'Earthquake through the window - what would you see, what would you feel?: asking pupils to picture for themselves what an earthquake through the window might look like'; 'Sand on a sill: What will happen to a sand grain left on a window sill? - a rock cycle discussion'; 'From clay balls to the structure of the Earth: a discussion of how physics can be used to probe Earth's structure'; 'Is there life in this soil sample? - questions to consolidate pupil understanding of soil-formation'; 'The 'What could hurt you here?' approach to field safety - teaching how to keep safe during fieldwork and other outdoor activities'; 'What was it like to be there - in the rocky world? - bringing the formation of solid rock to life by imagining yourself there when it formed'; 'Fieldwork: the 'All powerful' strategy - discussing geological histories in imaginative ways' and 'Fieldwork - interactive re-creation: activities using simple transportable apparatus to simulate features in the field'. Two of these Earthlearningidea activities are given in full, as examples of the Earthlearningidea approach in general, and the use of the 'thought experiment' ideas to generate deep questioning and discussion in the lab and field, in particular.

\section{Manuscript:}

Received: Quadrennial Conference of the International Geoscience Education Organization

Accepted: 14/01/2018

Citation: King C., Kennett P., Devon E 2018.Earthlearningidea: promoting deep questioning in lab and field. Terræ Didatica, 14(3):263-270. URL: http:// www.ige.unicamp.br/terraedidatica/.

Keywords: Earthlearningidea, handson activities, thought experiments, fieldwork, labwork

Thematic line: Teaching of Geosciences and Natural Sciences for School-Level Education and Teacher Training

\section{The Earthlearningidea initiative}

Earthlearningidea was developed as a response to the UNESCO International Year of Planet Earth (IYPE) in 2008. After a bid for funding to develop international geoscience education workshops was unsuccessful, three members of the Earth Science Education Unit, based at Keele University in the UK, decided to 'go it alone' on a voluntary basis by publishing ideas for teaching Earth science on a website, for free downloading across the world. The activities were deliberately chosen to demonstrate Earth processes using minimal equipment, particularly applicable in developing countries.
One new idea was published each week during the IYPE and the project was welcomed by colleagues across the world. At that stage, one colleague offered to translate them into Spanish, an offer that was quickly welcomed. Following the first successful year, publication continued the following year. During this time it became apparent that, whilst the Earthlearningideas (ELIs) were being used in some developing countries, their main usage was in more developed countries. Thus it was decided to publish ideas that required higher levels of abstract thinking skills and/or equipment likely to be available in science labs in more devel- 


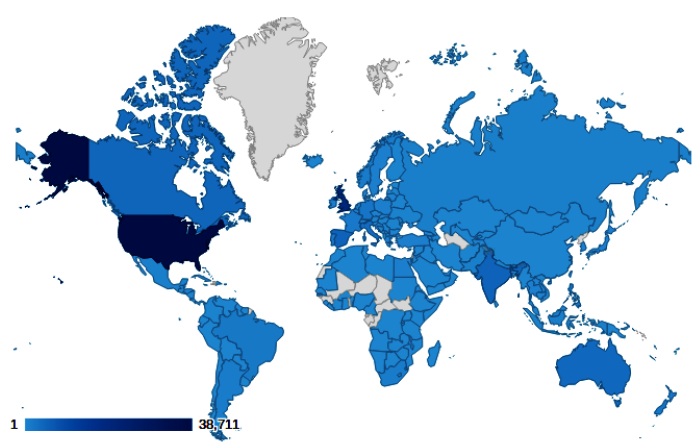

Figure 1. Countries that have visited the Earthlearningidea blog, the darker the colour, the more hits - data provided by Google Analytics

oped areas, as ELI+ activities. At a later stage, ELIs for younger pupils were added too.

Currently ELIs are being published on the Earthlearningidea website (ELI website) every two weeks, and more than 280 ideas have now appeared in English. Translators around the world have kindly offered to translate the ideas into their own languages and more than 900 translations can now be accessed through the website in Spanish, Catalan, Norwegian, Italian, German, Portuguese, Polish, Slovakian, Chinese Mandarin, Japanese, South Korean and Tamil. So far, nearly 3.5 million pdfs of the ideas have been downloaded, averaging more than 40,000 per month. The activities have been used in teacher training in a number of countries, as recorded in the Earthlearningidea blog at http://earthlearningidea.blogspot.co.uk/ The blog has so far been accessed in the 202 countries as shown in Figure 1.

The top ten countries are:

- United States

- United Kingdom

- India

- Spain

- Canada

- Australia

- Italy

- Philippines

- New Zealand

- Germany

The blog has also been accessed in more than 10,000 towns and cities worldwide.

\section{Analysis of the Earthlearningidea activities}

An analysis was published in 2016 of the different approaches used in the ideas published to that date (King, 2017). The analysis used the categories shown in Table 1. Despite there being a good deal of overlap in some categories, so that some ELIs fell into more than one category, the pattern emerged as shown in Table 1.

The 30 'unattributed' activities included mainly games, discussion and misconception activities, and activities concerning famous geoscientists.

The analysis shows that nearly half the Earthlearningidea activities use physical models and that most of these are used to illustrate Earth phenomena. Many of the activities involve observation or thought experiments, whilst some focus on investigation; only a small number use diagram-based models or involve the teaching of basic skills.

The thought experiments were deliberately focussed on promoting deep understanding through deep questioning in the lab and field. They include these examples:

- 'Earthquake through the window - what would you see, what would you feel?: asking pupils to picture for themselves what an earthquake through the window might look like';

- 'Sand on a sill: What will happen to a sand grain left on a window sill? - a rock cycle discussion';

- 'From clay balls to the structure of the Earth: a discussion of how physics can be used to probe Earth's structure';

- 'Is there life in this soil sample? - questions to consolidate pupil understanding of soil-formation';

Table 1. An analysis of the first 250 Earthlearningidea activities

\begin{tabular}{l|c|c}
\hline Type of activity & $\begin{array}{c}\text { No. of activ- } \\
\text { ities of this } \\
\text { type/250 }\end{array}$ & $\begin{array}{c}\text { Percentage of } \\
\text { activities of } \\
\text { this type/250 }\end{array}$ \\
\hline Basic skills & 11 & 4 \\
\hline Observation & 40 & 16 \\
\hline Illustration & 98 & 39 \\
\hline Investigation & 26 & 10 \\
\hline $\begin{array}{l}\text { Diagrammatic } \\
\text { models }\end{array}$ & 13 & 5 \\
\hline Physical models & 111 & 44 \\
\hline $\begin{array}{l}\text { Thought } \\
\text { experiments }\end{array}$ & 32 & 13 \\
\hline Unattributed & 30 & 12 \\
\hline
\end{tabular}


- 'The 'What could hurt you here?' approach to field safety - teaching how to keep safe during fieldwork and other outdoor activities';

- What was it like to be there - in the rocky world? - bringing the formation of solid rock to life by imagining yourself there when it formed';

- 'Fieldwork: the 'All powerful' strategy - discussing geological histories in imaginative ways';

- 'Fieldwork - interactive re-creation: activities using simple transportable apparatus to simulate features in the field'.

\section{Examples of Earthlearningideas designed to promote deep questioning}

Examples using these thought experiment approaches are given below (Figs. 2 up to 5). They are used here both to illustrate the overall. Earthlearningidea approach and to highlight the use of thought experiments.

\subsection{A field example: 'Fieldwork: the 'All power- ful' strategy - discussing geological histories in imaginative ways'}

Ask your pupils to examine a rock exposure in the field in the normal ways. Bring together their thinking in a plenary activity at the end, by asking: 'If I were 'All Powerful' what would I have to do to re-create the view you see before you?'

To give them an idea of how 'All powerful' your powers are, you will probably have to explain how you would begin, as in the examples below.

\section{The 'All Powerful' strategy - a Jurassic Quarry example in the UK}

The pupils have examined a small quarry into Jurassic limestone and have found some well-bedded cream-coloured rocks containing lots of broken shells; some of the layers are made entirely of small balls of calcium carbonate, called ooids. To answer the 'All powerful' question, pupils would need to know that most limestones are deposited in tropical and subtropical seas, that ooids form in shallow sandbanks and that tropical shells are broken up by waves on sandbanks and beaches.

Begin with, 'If I were 'All Powerful' and wanted to re-create the view you see before you, I would move the land we're standing on today near to latitude about $30^{\circ} \mathrm{N}$ and would push it down until it

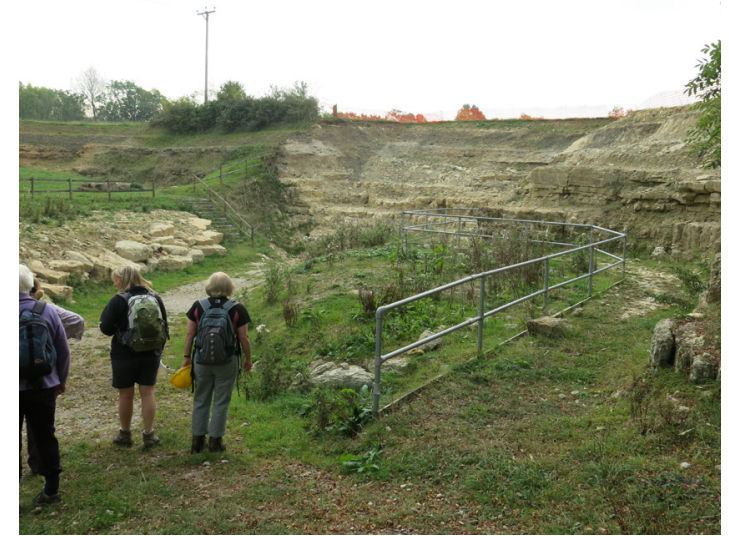

Figure 2. Coombs Quarry, Buckinghamshire, England. Photo: Nikki Edwards. Image owned by Anne Burgess and licensed for reuse under the Creative Commons Attribution-ShareAlike 2.0 license

was just below sea level - what should I do next?'

Some suitable answers might be:

- flood the area with a shallow sea;

- $\quad$ ensure that lots of shelly animals were living in the shallow sea (there was lots of food and oxygen - a good environment for life);

- build banks of carbonate sand in several areas, with a few tropical islands;

- create storms to smash up and deposit broken shell fragments;

- cause the area to sink, allowing more and more sediment to build up on top;

- make the area sink so far that the pressure of the overlying sediments and the liquids flowing around the grains change the carbonate sands into limestones;

- move everything thousands of kilometres to its current latitude in England (some $52^{\circ} \mathrm{N}$ );

- make the land rise, and slowly remove (erode) the overlying sedimentary rocks;

- make the surface rise to its current altitude, around $100 \mathrm{~m}$ above sea level;

- show humans that the rock is valuable as a building stone;

- $\quad$ encourage them to excavate a quarry.

\section{The 'All Powerful' strategy - an example of a view of the Deccan Traps in India}

Begin, 'If I were 'All Powerful' and wanted to re-create the view you see before you, I would move the land we're standing on today over a 'hot spot' producing lots of fast-flowing lava that, when 
it cooled, recorded the latitude at which it formed

$\left(30^{\circ} \mathrm{S}\right)$ - what should I do next?'

The answers might be:

- ensure that the lava keeps flowing, to build up one of the thickest and widest sequences of lava flows on Earth;

- move the area thousands of kilometres north to its current position $\left(18^{\circ} \mathrm{N}\right)$;

- $\quad$ push the land up so that rivers start cutting down into the lavas;

- keep pushing the land up and create rain storms so rivers cut down, making valleys;

- ensure the land reaches its current height (around $1000 \mathrm{~m}$ or $1 \mathrm{~km}$ );

- encourage humans to build a dam to make a reservoir, to build settlements and to farm the land;

- encourage the Indian government to build a sight-seeing area on the edge of the road.

\section{The 'All Powerful' strategy - an example of an unconformity at Siccar Point in Scotland}

Begin as, 'If I were 'All Powerful' and wanted to re-create the view you see before you, I would move the land we're standing on today below sea level so that lots of layers of sediment built up on it - what should I do next?'

Answers might be:

- make the sea floor subside so that more and more sediment builds up;

- use the pressure of the layers above and the circulating fluids to change the sediments into sedimentary rock;

- squeeze the rocks from the side so that they became tightly folded into mountains, making some of the layers near vertical;

- $\quad$ erode the mountains down to sea level;

- make the surface sink and flood it with water;

- lay down lots more layers of sediment;

- bury these in even more sediment;

- change the sediments into sedimentary rocks;

- squeeze them again until the layers are tilted and forced up into mountains;

- erode away the overlying rocks to that we can see the view today.

The back up

Title: Fieldwork: the 'All powerful' strategy

Subtitle: Discussing geological histories in imaginative ways

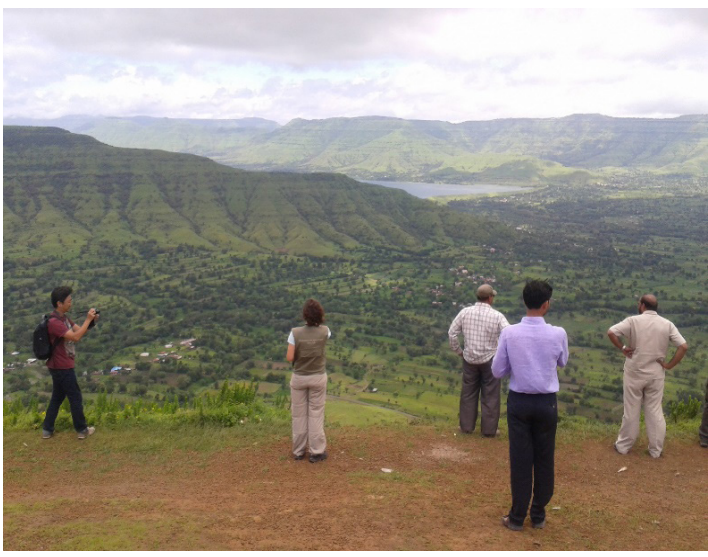

Figure 3. view of the Deccan Traps, India. Photo: Chris King

Topic: A plenary activity to help pupils to imagine the geological history of a rock exposure or landscape.

- Age range of pupils: 7 - 100 years

- Time needed to complete activity: 10 minutes

- Pupil learning outcomes: Pupils can:

- imagine the stages of a geological history;

- describe the processes necessary for that geological history to have taken place;

- begin to visualise the scope, scale and time spans of the processes involved.

\section{Context:}

This activity uses a 'deep questioning' approach to a plenary fieldwork activity, by asking what series of events would be necessary for the view before the pupils to be recreated. The activity can be used at a range of scales from a small quarry to a landscape-wide interpretation.

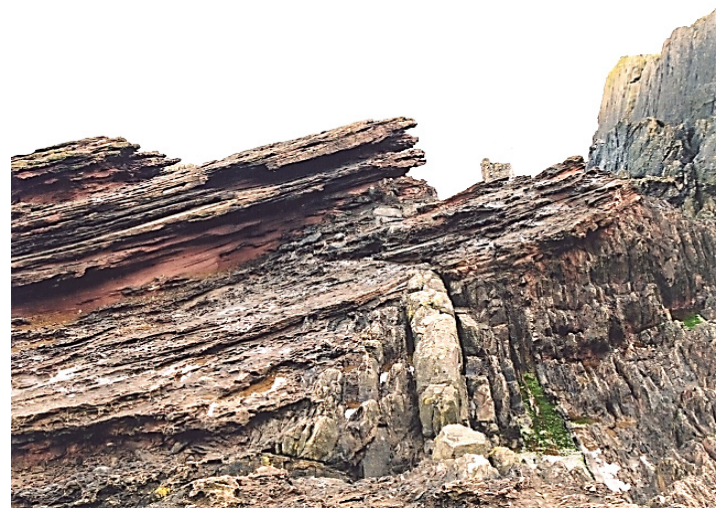

Figure 4. Siccar Point, Berwickshire, Scotland 


\section{Following up the activity:}

Try the "What was it like to be there - in the rocky world?' Earthlearningidea or some of the other fieldwork Earthlearningideas.

\section{Underlying principles:}

- All rock sequences and their characteristics can be explained as a series of discrete events.

- Many geological events happen on a landscape-sized scale, that are often most easy to visualise in the field.

\section{Thinking skill development:}

This activity uses an imaginative and creative approach to the visualisation of geological histories, involving construction of past patterns and a metacognitive approach to explanations.

\section{Resource list:}

- a suitable site and imagination

Source: Devised by Chris King of the Earthlearningidea Team.

(This Earthlearningidea appears on the ELI website at: http://www.earthlearningidea.com/ PDF/203_All_powerful.pdf)

\subsection{A lab example: 'Sand on a sill: What will hap- pen to a sand grain left on a window sill? - a rock cycle discussion'}

Take a coloured ${ }^{\star}$ grain of sand ${ }^{\star \star}$ and place it on a windowsill outside the classroom. Draw a circle around it to show where it has been placed. Then ask groups of pupils to discuss what might happen to the sand. They might need prompting by such questions as: 'What might happen next?', 'And then?' or 'Can you think of another idea?'

Pupils' stories are only constrained by their imagination. Most stories will involve parts of the rock cycle - the main focus of this discussion.

\section{The stories might include:}

- The wind blows it off

And then?

- It falls to the ground

And then?

- It is washed away by rain into a drain

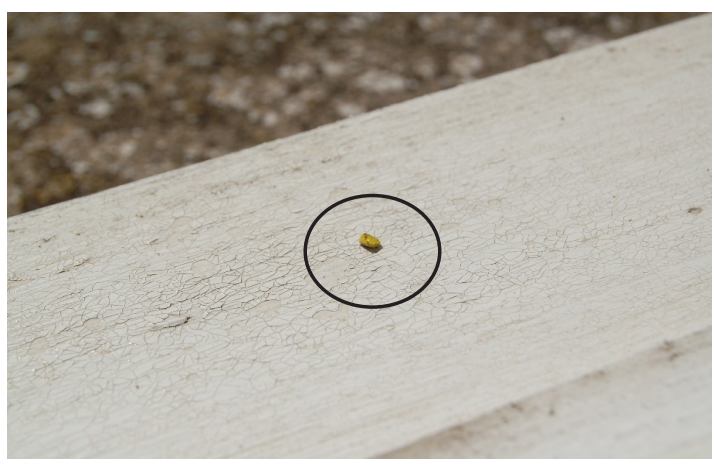

Figure 5. A $2 \mathrm{~mm}$ diameter grain of yellow-coloured sand on a windowsill with a circle drawn around it (Chris King)

And then?

- It is washed into a river and settles to the bottom

And then?

- It is picked up and washed into the sea

And then?

- It settles to the sea bed

And then?

- It is buried by more sand

And then?

- It hardens into sandstone

And then?

- It is raised up into a mountain during a mountain-building event

And then?

- It is eroded and the cycle begins again

Another idea

- Rainwater washes it off the windowsill

- It falls into the soil

- It stays in the soil for ever

Another idea

- Wind blows it off

- It lands on a path

- Someone steps on the sand grain - it becomes stuck into the sole of their trainer

- It falls off on a road

- It is crushed by a car tyre

- The smaller grains get washed into a gutter and then a drain and a river 
- More sand builds up and the sand is buried for a very long time

Another idea

- A painter brushes it off the windowsill before painting the sill again

- It lands in the soil

- Weeds grow in the soil

- When the weeds are pulled up, the sand grain is in the attached soil

- It is taken to the refuse dump and thrown in the 'garden waste' skip

- It is recycled to make compost

- It is sold in a garden centre

- It is used to fertilise the soil somewhere else

Another idea

- After being blown onto the soil, the soil builds up

- It is buried as more and more sediment is laid down on top

- It eventually becomes a sedimentary rock

- It becomes metamorphosed to metamorphic rock

- It melts and is intruded or extruded as igneous rock

- It is recycled again as part of the rock cycle

After your class discussion:

- ask your class to check on the sand grain every day;

- if it falls off, get them to look for it on the ground beneath the windowsill and talk about what might happen next;

- revisit the discussion after six months to see how much of it they have remembered and also, what links with Earth cycles they can make (e.g. links with the rock cycle, the water cycle (rain, stream), biological cycles (soil), atmospheric cycles (wind)).

You can colour a grain of sand brightly with paint, such as paint for touching up cars, or you can buy brightly-coloured sand or gravel from the internet or aquarium-sellers

* Use any appropriate size of grain. Sand sizes are measured by geologists using the Wentworth Scale - according to this scale $2 \mathrm{~mm}$ diameter is the largest size of sand grains (which range from $2 \mathrm{~mm}-0.125 \mathrm{~mm}(1 / 8 \mathrm{~mm})$ in size), particles larger than $2 \mathrm{~mm}$ are called granules; larger sizes are pebbles, cobbles and boulders, smaller sizes are silt and clay.

\section{The back up}

Title: Sand on a sill

Subtitle: What will happen to a sand grain left on a window sill? - a rock cycle discussion

Topic: A pupil group discussion activity based on what will happen to a sand grain left on a windowsill.

Age range of pupils: 5 - 15 years

Time needed to complete activity: 10 minutes

Pupil learning outcomes: Pupils can:

- explain different processes that could move sand grains;

- describe where sand grains might be 'stored' as part of the rock cycle;

- describe creative ways of moving and storing sand grains;

- link their explanations with other Earth cycles.

\section{Context:}

This discussion activity has been devised to encourage pupils to think about rock cycle processes in the context of the area outside their own school. By leading the small group discussion using questions such as: 'What might happen next?', 'And then?' or 'Can you think of another idea?', teachers should be able to encourage pupils to consider a range of different processes and products of the rock cycle and how these link to other Earth cycles, as below (Table. 2):

\section{Following up the activity:}

Ask if the stories would be different with larger particles (pebbles, cobbles, boulders) or smaller particles (finer sand, silt or clay particles).

Ask pupils to draw pictures showing what happens to the grain of sand or write a story 'The Adventures of Sandy Grain'.

\section{Underlying principles:}

- The rock and other cycles can be considered as series of processes and products.

- Rock cycle processes link to other Earth cycles.

- Most sand grains are eroded grains of quartz (silicon dioxide), often coated in orange-red iron oxide. The quartz minerals originally crystallised out from a magma as it cooled and solidified into an igneous rock, before becoming eroded (as part of the rock cycle). 
Table. 2

\begin{tabular}{c|c}
\hline $\begin{array}{c}\text { Rock cycle processes } \\
\text { break-up or chemical } \\
\text { breakdown }\end{array}$ & $\begin{array}{c}\text { Links to other Earth cycles } \\
\text { linked to biological cycles }\end{array}$ \\
\hline $\begin{array}{c}\text { Erosion of sand by } \\
\text { wind or water }\end{array}$ & $\begin{array}{c}\text { Wind as part of the } \\
\text { atmospheric cycle }\end{array}$ \\
\cline { 1 - 1 } $\begin{array}{c}\text { Transportation of sand } \\
\text { by wind or water }\end{array}$ & Water as part of the water \\
cycle
\end{tabular}

The discussion might include these rock cycle products:

\begin{tabular}{c}
\hline Rock cycle products \\
\hline Soil \\
\hline Sediment \\
\hline Sediment sequence \\
\hline Sedimentary rock \\
\hline Metamorphic rock \\
\hline Igneous rock \\
\hline Deformed rock (by folding or faulting)
\end{tabular}

\section{Thinking skill development:}

Pupils have to apply their knowledge and imagination to the instance of a sand grain on the sill, by constructing ideas of what might happen to the grain, engaging in argumentation and cognitive conflict with others in their groups, which will develop metacognitive skills. Matching their ideas to real Earth processes involves bridging.

\section{Resource list:}

- a sand grain (e.g. around $2 \mathrm{~mm}$ across)

- brightly-coloured paint to colour the grain (car touch-up paint is often readily available) or use of a pre-coloured grain (e.g. from the internet or aquarium suppliers)

\section{Useful links:}

See the range of other Earthlearningideas related to the rock cycle, http://www.earthlearningidea.com

Source: Chris King of the Earthlearningidea Team.

(This Earthlearningidea appears on the ELI website at: http://www.earthlearningidea.com/ PDF/219_Sand_on_sill.pdf)

\section{A conclusion}

These thought experiment ideas have been trialled informally on people ranging from primary age children to practicing teachers and teachers in training in a variety of countries, and have always provoked excellent discussion and good evaluation feedback.

\section{Acknowledgements}

The ELI Team wishes to thank the following people and organisations for their support of Earthlearningidea:

- Geologists' Association, Curry Fund for a grant to host this website on a dedicated server from July 2014.The Applied and Environmental Geophysics Research Group at Keele University for their generosity in hosting this website from November 2008 to July 2014 free of charge.

- José Sellés Martínez - Spanish translation by AulaGEA, a service for teachers and learners of the Dept. of Geology of the University of Buenos Aires La traducción al español ha sido realizada por Aulagea, el programa de extensión del Departamento de Geología de la Facultad de Ciencias Exactas y Naturales de la Universidad de Buenos Aires.

- Merethe Frøyland - Norwegian translations by Kari Beate Remmen and Anne Kristine Byhring, sponsored by the Norwegian Committee of the Year of Planet Earth - Geologi.No

- Roberto Greco - Professor Dr. Roberto Greco Instituto de Geociências - Unicamp co-ordinated the Italian translations until 2011 and has co-ordinated the Portuguese translations since 2014. Portuguese translations are hosted on a specially designed website by Tatiane Carolina Morellato an Unicamp students. Translations are by Tatiane Carolina Morellato, Fabiana Giaretta, Gustavo José Lara Campos (Unicamp students) Revision by: Unicamp PhD students: Luiz Anselmo Consta v.14 
Nascimento Ifanger, Carolina Baldin, Prof. Ana Elisa Silva de Abreu (UNICAMP), Prof. Carolina Zabini (UNICAMP), Prof. Reginaldo Luiz Fernandes de Souza (UEA). Earth Learning Idea videos: Unicamp students: Erica Rodrigues Soares, Bruna Cristina Gama Campagnucci, Bruna Eduarda de Almeida Valença, Secondary school students: Andreza Aparecida Machado, Luiz Antonio Pereira Ferraz, Sthefani Archanjo Silva. Geoideias facebook page: Tatiane Carolina Morellato, Bruna Eduarda de Almeida Valeça, Caroline Araujo, Flavia Miyuki Kojima, all Unicamp students.

- Maddalena Macario - Italian translations. Maddalena is studying for a doctorate in the University of Camerino. Her research project focuses on teaching methods and resources in the Earth Sciences. She is also involved with other teachers in UNICAMearth that aims to address the teaching-learning of Earth Science in Italian schools (elementary, middle and high schools). Lorenzo Lancellotti, a collaborator in the UNICAMearth project, is assisting with these translations, as is Prof. Eleonora Paris. Some translations by Nicoletta Scattolin and her students and by Giulia Realdon.

- Dirk Felzmann - German translations by Julia Brinkmann, Dirk Felzmann, Florian Wetzel, Silke Rönnebeck, Sylvia Brink, Kai Frings, supported by the Department for Geography Education, Institute for Science Education, Leibniz University, Hannover. Dominik Conrad runs an Earthlearningidea-based course with his students at the Ludwigsburg University of Education. where his students translate and present some Earthlearningidea activities.

- Celso Dal Ré Carneiro - Portuguese translations by Celso Dal Ré Carneiro, Institute of Geosciences, Campinas State University, Campinas, Sao Paulo with Nádia C. M. Hoffman, formerly undergraduate in geology, and Gustavo H. Teramatsu, formerly undergraduate in geography, both of Campinas State University.

- Xavier Juan - Catalan translations by Xavier Juan, vice-president of the AEPECT (Asociación Española para la enseñanza de las Ciencias de la Terra) and Spanish co-ordinator for Science across the world.

- Pawel Wolniewicz - Polish translations by Pawel Wolniewicz, assistant professor of Geology in the Institute of Geology, Faculty of Geographical and Geological Sciences, Adam
Mickiewicz University, Poznan, Poland, and an assistant curator of the Poznan Earth Science Museum. Pawel also runs a blog devoted mostly to geology and palaeontology which aims to promote the Earth Sciences to the general public. Anna Odachowska M.Sc., a teacher of geography and English, is also translating ELIs into Polish.

- Peter Fararik - Slovakian translations by Peter Fararik and his team working for The Lepšia geografia (Better geography) project.

- Shao Yanxiu - Mandarin Chinese translations by Shao Yanxiu and Zhang Lianhai of the Geoidea team. Geoidea is a network platform for teachers and students interested in Geoscience. Mandarin Chinese translations also by Julia Yuan Li, M.Eng. Imperial College, London.

- Takashi Sawaguchi, and Megumi Watarai - Japanese translations by Prof. Takashi Sawaguchi (Natural Science Laboratory, Toyo University) and Dr. Megumi Watarai (Ph.D as a palaeontologist from Tsukuba University - now working at a private high school as a part-time teacher)

- Michael Anjello Jothi Rajan - Tamil translations by Jothi Rajan, Associate Professor Dept. of Physics, Head Dept. of Religion and Value Education, Arul Anandar College (Autonomous), Karumathur 625 514, Tamil $\mathrm{Nadu}$, India

- IUGS-COGE - International Union of Geological Sciences - Commission on Geoscience Education: for a donation of US $\$ 1,000$ for the development of this project.

- IGEO - The International Geoscience Education Organisation for international networking support

- ESEU - The Earth Science Education Unit UK for sharing many of its activities

- ESTA - The Earth Science Teachers' Association for inspiring many of the activities

\section{References}

Earthlearningidea website: http://www.earthlearningidea.com

King C. 2017. Fostering deep understanding through the use of geoscience investigations, models and thought experiments. The Earth Science Education Unit and Earthlearningidea experiences. In: Vasconcelos C. ed. 2017. Geoscience education: indoor and outdoor. Switzerland: Springer. p. 3-23. 